\title{
DESIGNER - SUPPORTING TEACHERS EXPERIENCE IN LEARNING MANAGEMENT SYSTEMS
}

\author{
Silvia Baldiris ${ }^{1}$, Sabine Graf $^{2}$, Jorge Hernandez ${ }^{1}$, Ramon Fabregat ${ }^{1}$ and \\ Nestor Duque ${ }^{3}$ \\ ${ }^{1}$ Institute of Informatics and Aplications (IIiA) University of Girona, Girona, Spain \\ (baldiris,ramon,jehernan)@eia.udg.es \\ ${ }^{2}$ School of Computing and Information Systems, Athabasca University, Canada \\ sabineg@athabascau.ca \\ ${ }^{3}$ National University of Colombia, Campus Manizales, Manizales, Colombia, \\ ndduqueme@unal.edu.co
}

\begin{abstract}
In the lifelong learning context, the efficiency of learning is measured according to the users' achievement of the target competences. However, in a virtual learning environment supporting the competence development process ends up being an elusive and time-consuming task for teachers or instructional designers. In this paper, we introduce Designer, an approach for teachers to help them in designing courses via a semi-automatic design process based on dynamic user modeling and adaptive learning design generation. A qualitative and quantitative evaluation demonstrated the effectiveness of Designer in supporting teachers to create adaptive courses.
\end{abstract}

Keywords: Learning design generation, standards, adaptation, user modeling, planning.

\section{Introduction}

The generation of learning designs adjusted to user characteristics (i.e., learning styles and competences) [1],[2],[3] is not an easy problem, in particular for the teachers. Actually, this problem implies that teachers need to know the different instructional theories to support the design generation. They also need to control the different user variables to consider in the learning design construction such as users' learning styles and competences, among others. Furthermore, teachers need to know how to develop standardized learning designs for the specific learning platform they use.

In this paper, we introduce Designer, an approach for teachers to help them in designing courses via a semi-automatic design process based on competence definitions, user modelling and adaptation task. The main elements of our approach include: 1) the generation of a standardized and conditional learning design adjusted to IMS Learning Design specification; 2) the dynamic modelling of users' competences and learning styles and 3 ) the automatic generation of learning designs 
based on planning techniques that consider the users' competences and learning styles. The aim of Designer is therefore to enable teachers to easily create standardized and adaptive learning designs by using a semi-automatic approach.

The paper is structured as follows. The second section introduces an analysis of the state of the art about the learning design generation process. In the third section, the general framework of our approach is introduced. The fourth section describes the two different planning problems for generating the learning design. The fifth and sixth sections describe some implementation details and the evaluation of the proposed semi-automatic learning design generation process respectively and finally the seventh section presents some concluding remarks and proposals for future work.

\section{STATE OF THE ART ABOUT LEARNING DESIGN GENERATION PROCESS}

A well-accepted definition for a learning design process is the following: the process that should be followed by teachers in order to plan and to prepare the instruction [4]. This process could be developed: 1) manually where teacher develop the design completely, 2) semi-automatically, with only a few inputs from the teachers or 3) automatically without teacher's intervention.

With the purpose to facilitate teachers the task of creating learning design manually, different solutions have been proposed, among them: Recourse [5], CopperAuthor [6], Reload[7], Collage[8], MOT+[9] and LAMS[10], ASK-LDT [11].

Semi- automatic and automatic learning design generation have been faced througt different points of view. In [3], [12] Karampiperis and Sampson proposed an approach based on a knowledge ontology, learning object metadata and competences which uses a weighted shortest path algorithms to generate an optimum learning path.

Duque et al. [13] proposed a multi-agent system for planning and execution of virtual personalized courses. Castillo et al. [14], using the SIADEX planner, addressed the problem to dynamically generate the planning domain based on the learning objects' metadata. Morales et al. [15] introduced a new approach that extends their previous work where they propose a multi-plan generation approach based on the user performance in different tests not using conditional planning. Ullrich and Melis [16] proposed a courseware generation framework based on HTN planning, PAIGOS, which generates structured courses that are adapted to a variety of learning goals and to learners' competencies.

In the state of the art, some researchers mention that the dynamic learning style modelling process is an interesting issue to research [17], [18], [19]. However, this dynamic process is not addressed until now in the learning design generation process. This means that it is not specified how this dynamic process affects the generated designs in the execution time. This paper addresses the dynamic process in the learning design and is based on our investigations in previous work about dynamic user modeling based on learning styles [20].

On the other hand, the big effort developed for international organization of standardizations has not been considered in the teacher's normal activities. Many 
teachers do not know the specifications and it is common when teachers are faced to use the standards they feel the standards are difficult to use.

In our research, we aim at alleviating the workload for teachers of creating adaptive courses by reducing the complexity involved in authoring standardized and adaptive learning designs adjusted to their students' characteristics (competences and learning styles), which are inferred through a dynamic user modelling approach. In the next section, we show the general elements of our framework.

\section{GENERAL FRAMEWORK FOR LEARNING DESIGN GENERATION}

Figure 1 shows the general elements of our framework. The Competence Definition permits to define appropriate performances that should be demonstrated by a person on a specific context. The competence definition consists of: Competence General Information, Competence Elements which are smaller learning purposes, Didactical Guidelines and the Competence Context. Competence Elements in turn describe the Essential Knowledge and Competence Evidence.

The User Model Initialization identifies and stores the initial state of the user model variables using the Learner Information Profile (LIP) Specification [21] schema. The Local Learning Objects and Activity Metadata Definition is referred to label the learning objects develop by teachers (internal objects) with metadata. Distributed Learning Objects Metadata Searching is a mechanism supported by agent technologies and its main purpose is to consider external learning objects the learning designs generation process.

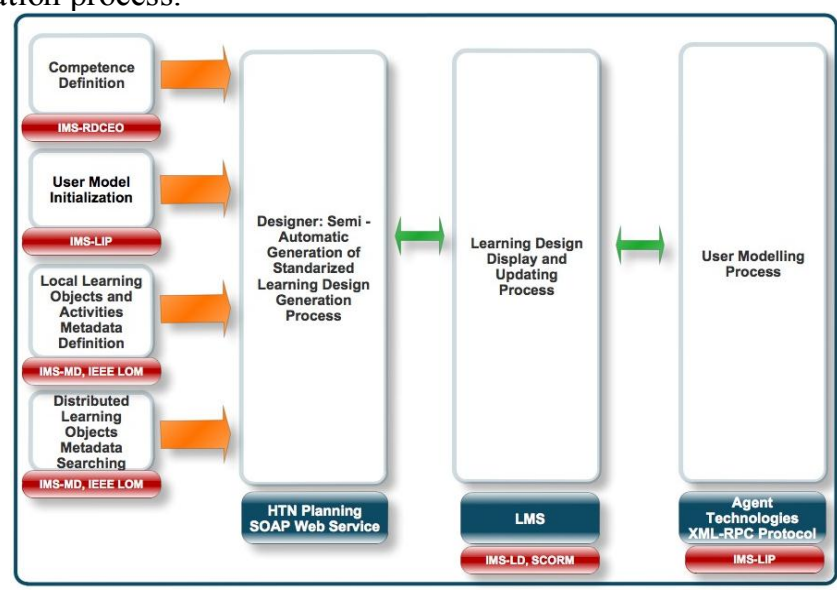

Figure 1. Proposed framework for learning design generation

Designer: Semi-Automatic Standardized Learning Design Generation Process, is in charge of designing adapted teaching-learning experience (i.e. the creation of adaptive learning paths) adjusted to the IMS-LD level B [22]. The generated design can be displayed and updated later according to the performance and characteristics of the students, captured through the user modelling process. 
The Learning Design Display and Updating Process is the process in charge for presenting and maintaining learning design execution according to the user model.

The User Modelling Process aims at creating and maintaining an up-to-date user model. We consider two user characteristics, competences and learning styles.

For addressing the overall adaptation process we consider two perspectives: design time (when the course is created and composed in the LMS) and run time (when learners are learning in the course). At the design time, the necessary information for the Designer (agent who generates the course) is developed and constructed and the execution time, the generated learning design is displayed in the LMS [23] and the user behaviour is monitoring.

\section{PLANNING LEARNING DESIGN GENERATION}

As was mentioned before the Designer is in charge of designing adapted teachinglearning experience. We have modelled the problem of learning design generation as a planning problem, using HTN planning as a generation mechanism. HTN planning [24] was selected because the course domain is constructed from the competence definition, which has a hierarchical structure.

HTN planning or actually any planning paradigm imply to face the domain and problem generation which are inputs for the planners. The planning domain describes all actions needed to achieve one or more goals expressed in the planning problem.

The planning problem describes the initial state of all variables which participate in the problem and the goals. Then, we consider two different planning problems. The first one for generating a learning design based only on the competence definition provided by teachers, considering the initial state of the users' competence. In the second planning problem, we consider both the users' learning styles and competence.

The core of the first scenario is the generation of an adequate course for all students registered to a class that take into account only the definition of the competence provided by the teacher.

The initial state is constructed using the procedures getMetadata and getOrganization. getOrganization takes the information defined in the competence definition and converts it in a term list. Furthermore, getMetadata analyses the learning objects metadata files and converts them in a term list.

The main method in the planning domain is generateIMSLD, which uses the information provided by the organization list structure iterating over it recursively in order to construct the plan.

In the second scenario, we extended the adaptation in the first scenario by additionally considering students' learning styles in the adaptation process. The core of the adaptation process based on learning styles is to select the best order to present learning resource types according to the learning style information, as suggested for example in [25]. Results of this study [25] indicated that students are more satisfied with their learning experiences and need less time for learning if they receive learning objects ordered according with their learning style preferences. In order to include the adaptation based on learning styles we have created another method called 
GetPreferences for obtaining the information related to the students' learning style preferences and include it in the initial state of the user model [20].

\section{INTEGRATION UPON dotLRN}

In order to integrate our proposals upon OpenACS/.LRN, the following implementations were developed: 1) Designer Service v1.0, implements a planning web service based on SOAP, which listens user's requests and sends as a reply an IMS-LD unit of learning. 2) Designer Client v1.0 Package: implements a web service client upon dotLRN in order to send planning requests to the Designer Service and process its responses. The parameters that the Planner Clients sends in its requests are the IMS-RDCEO of a course generated by the Competences Package, the list of learning content metadata URLs associated to the course and the users' preferences. The Planner Engine responds with an adapted course, which the planner client automatically loads and deploys as an adapted learners' unit of learning using Grail [23]. For users it is not necessary the technical management of any specification because we have created users interfaces.

\section{EVALUATION}

The main purpose of the evaluation is to verify the teachers' satisfaction with our solution offered for generating adapted learning designs based on students' competences and learning styles. The principal actor in this evaluation is the teacher who evaluated the approach considering three dimensions:

- The main elements of the learning and teaching process description (Competence definition, metadata specification and the link between both).

- The semi-automatic generation process.

- The adaptation process.

Six teachers from Universitat of Gerona participated in this study. The teachers were from different fields including pedagogy, economy, law, psychology, tourism and administration science. Teachers have different levels of experience in online learning in particular in the use of virtual learning environments.

Quantitative analysis was used to get data about teachers' perception on how important the proposed dimensions (described at the beginning of this section) are and how our solution satisfies their expectation about them. All teachers were asked to fill out a survey, created according to a Gap Service Quality Model [26]. Gap Service Quality Model have been strongly validated in different domains to measure users satisfaction reporting good results [27]. The survey consisted of fifteen questions, including five questions for each of the three proposed dimensions in order to obtain feedback from the teachers about their perception of each dimension.

Figure 2 shows the results of the Gap analysis. In general, all teachers have assigned a high score to the importance and satisfaction for each dimension. The difference between importance and satisfaction (gap) for the proposed solutions is 
very small (least than 1 point out of 10). It means the proposed solution seems to meet the expectations of the teachers who participated in this study.

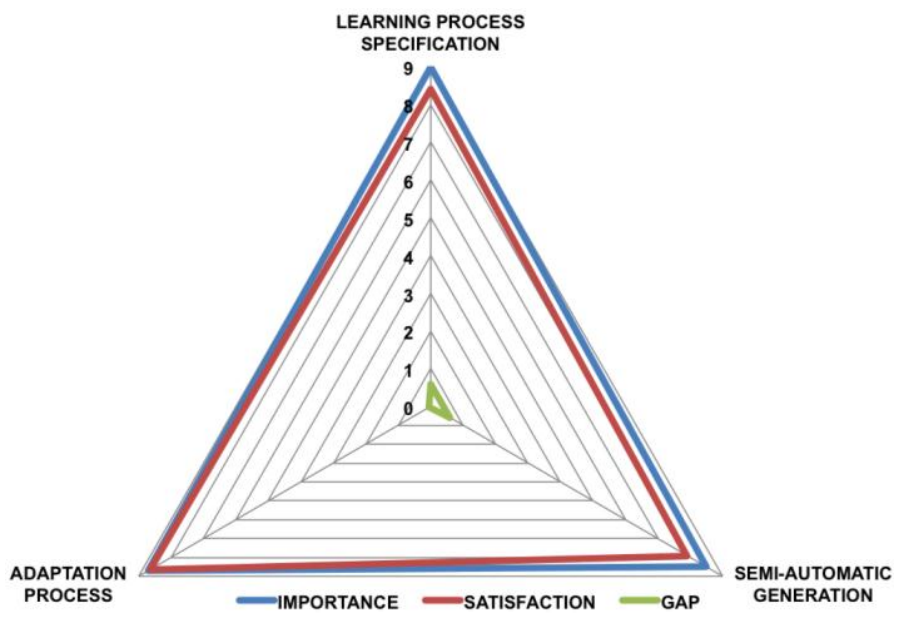

Figure 2. Gap Model Results

\section{Conclusions and future works}

Developing adaptive and standardized courses is very time-consuming for teachers. In this paper, we introduce an approach for reducing teachers' workload for generating standardized and adaptive learning designs. Designer: Semi-Automatic Standardized Learning Design Generator was introduced and evaluated.

Our evaluation showed that the participating teachers found our approach useful, especially for the possibility to easily create an IMS-LD and also for the possibility of providing learning paths adapted to the students' learning styles and competences. However, they also complained that the production of learning resources and virtual activities and its semantic relations through metadata requires an initial extra effort. But they also agreed that in subsequent opportunities, this effort decreases as the possibility of reutilization grows.

Future works will be oriented to take into account other students' features such as special needs and also teachers' preferred methodologies for learning design creation.

\section{References}

1. Graf, S., Kinshuk, D.: Providing Adaptive Courses in Learning Management Systems with Respect to Learning Styles. In: Richards, G. (ed.) Proceedings of the World Conference on ELearning in Corporate, Government, Healthcare, and Higher Education (e-Learn). pp. 2576-2583. AACE Press, Chesapeake, VA (2007).

2. Popescu, E.: Evaluating the impact of adaptation to learning styles in a Web-based educational system. Proceedings of the 8th International Conference on Advances in Web Based Learning (ICWL 2009) (2009). 

Learning. 6th IEEE International Conference on Advanced Learning Technologies. IEEE Computer Society Press (2006).

4. Reigeluth, C.M.: Instructional Design Theories and Models, a new paradigm of instructional theory. Laurence Erlbaum Associates (1999)

5. TENCompetence: Recourse, http://tencompetence-project.bolton.ac.uk/ldauthor/

6. Open Universiteit Nederland: CopperCore, http://coppercore.sourceforge.net/.

7. Bolton, U. of: Reusable eLearning Object Authoring \& Delivery (RELOAD).

8. Hernández-leo, D., Villasclaras-fernández, E.D., Asensio-pérez, J.I., Jorrín-abellán, I.M., Ruizrequies, I., Rubia-avi, B.: COLLAGE : A collaborative Learning Design editor based on patterns. Learning. 9, 58-71 (2006).

9. Paquette, G., De La Teja, I., Leonard, M., Lundgren-Cayrol, K., Marino, O.: An Instructional Engineering Method and Tool for the Design of Units of Learning. In: Koper Rob, T.C. (ed.) A Handbook on Modelling and Delivering Networked Education and Training. pp. 161-184 (2005)

10. LAMS: Learning Activity Management System, http://www.lamsinternational.com/.

11. Sampson, D., Karampiperis, P., Zervas, P.: ASK-LDT: A Web-Based Learning Scenarios Authoring Environment Based on IMS Learning Design. Advanced Technology for Learning (Discontinued). 2, (2005).

12. Karampiperis, P., Sampson, D.: Adaptive Learning Object Selection in Intelligent Learning Systems. Journal of Interactive Learning Research. 15, 389-407 (2004).

13. Duque Méndez, N.D., Ovalle Carranza, D.A., Jiménez Builes, J.A.: Artificial Intelligence For Automatic Generation Of Customized Courses. In: Bohman, E.P.P. (ed.) World Conference on Educational Multimedia, Hypermedia and Telecommunications. pp. 2693-2698 (2002)

14. Castillo, L., Morales, L., González-Ferrer, A., Fdez-Olivares, J., Borrajo, D., Onaindía, E.: Automatic generation of temporal planning domains for e-learning problems. Journal of Scheduling. 13, 347 - 362 (2009)

15. Morales, L., Castillo, L., Fernández-Olivares, J.: Planning for Conditional Learning Routes. In C, A.H.A. et al. (ed.) MICAI 2009: Advances in Artificial Intelligence. pp. 384-396. SpringerVerlag Berlin Heidelberg (2009).

16. Ullrich, C., Melis, E.: Pedagogically founded courseware generation based on HTN-planning. Expert Systems with Applications. 36, 9319-9332 (2009).

17. Graf, S., Liu, T.-chien: Supporting Teachers in Identifying Students ' Learning Styles in Learning Management Systems : An Automatic Student Modelling Approach. Educational Technology \& Society. 12, 3-14 (2009).

18. Ortigosa, A., Paredes, P., Rodriguez, P.: AH-questionnaire: An adaptive hierarchical questionnaire for learning styles. Computers \& Education. 54, 999-1005 (2010).

19. Carmona Márquez, C., Castillo Jordán, G., Valldeperas, E.M.: Modelo Bayesiano del Alumno basado en el Estilo de Aprendizaje y las Preferencias. IEEE-RITA Revista Iberoamericana de Tecnologías del Aprendizaje. 4, 139 - 146 (2009).

20. Baldiris, S., Graf, S., Fabregat, R.: Dynamic User Modeling and Adaptation based on Learning Styles for Supporting Semi-Automatic Generation of IMS Learning Design. The 11th IEEE International Conference on Advanced Learning Technologies. , Athens, Georgia, USA (2011).

21. IMS: IMS Learner Information Package Specification. (2001).
22. IMS: IMS Learning Design. Version 1.0. Final Specification. (2003).

23. Escobedo Del Cid, J.P., Valentín De La Fuente, L., Gutiérrez, S., Pardo, A., Delgado Kloos, C. Implementation of a Learning Design Run-Time Environment for the .LRN Learning Management System. JIME Special Issue: Adaptation and IMS Learning Design. 1-16 (2007).

24. Erol, K., James, H., Dana, N.: HTN planning: Complexity and expressivity. Twelfth National Conference on Artificial Intelligence (AAAI-94). pp. 1123-1128. AAAI Press/MIT Press, Seattle, Washington, USA (1994).

25. Popescu, E., Badica, C.: Providing Personalized Courses in a Web-Supported Learning Environment. IEEE/WIC/ACM International Conference on Web Intelligence and Intelligent Agent Technology - Workshops (2009).

26. Parasuraman, A., Zeithaml, V., Berry, L.: SERVQUAL- A Multiple-Item Scale for Measuring Consumer Perceptions of Service Quality. 64, 12-40 (1998).

27. Landrum, H., Prybutok, V., Zhang, X., Peak, D.: Measuring IS System Service Quality with SERVQUAL : Users' Perceptions of Relative Importance of the Five SERVPERF Dimensions. International Journal of an Emerging Transdiscipline. 12, 18-35 (2009). 